Neusa Sica da Rocha ${ }^{1,11}$

Marcelo Pio de Almeida Fleck $^{1,11, \mathrm{III}}$
Hospital de Clínicas. Universidade Federal do Rio Grande do Sul (UFRGS). Porto Alegre, RS, Brazil

Programa de Pós-Graduação em Ciências Médicas: Psiquiatria. UFRGS. Porto Alegre, RS, Brazil

III Departamento de Psiquiatria e Medicina Legal. UFRGS. Porto Alegre, RS, Brazil

\author{
Correspondence: \\ Neusa Sica da Rocha \\ Serviço de Psiquiatria \\ Hospital de Clínicas de Porto Alegre-UFRGS \\ Av. Ramiro Barcelos, $23504^{\circ}$ andar \\ 90003-035 Porto Alegre, RS, Brazil \\ E-mail: neusa-rocha@via-rs.net
}

\section{Validity of the Brazilian version of WHOQOL-BREF in depressed patients using Rasch modelling}

\author{
Validade da versão brasileira do \\ WHOQOL-BREF em pacientes \\ deprimidos usando o modelo de \\ Rasch
}

\begin{abstract}
OBJECTIVE: To assess the validity of the Brazilian version of the World Health Organization Quality of Life Instrument - Abbreviated version (WHOQOLBREF) in adults with major depression, using Rasch modelling.

METHODS: Study analyzing data from the baseline sample of the Longitudinal Investigation of Depression Outcomes in Brazil, including a total of 208 patients with major depression recruited in a primary care service in Porto Alegre (Southern Brazil), in 1999. The Center for Epidemiological Studies Depression Scale was used to assess intensity of depression; the WHOQOLBREF to assess generic quality of life; and the Composite International Diagnostic Interview version 2.1 for the diagnosis of depression.
\end{abstract}

RESULTS: In the Rasch analysis, the four domains of WHOQOL-BREF showed appropriate fit to this model. Some items needed adjustments: four items were rescored (pain, finances, services, and transport); two items (work and activity) were identified as having dependency of responses, and one item was deleted (sleep) due to multidimensionality.

CONCLUSIONS: The validation of the WHOQOL-BREF Brazilian version using Rasch analysis complements previous validation studies, evidencing the robustness of this instrument as a generic cross-cultural quality of life measure.

DESCRIPTORS: Depression. Quality of Life. Questionnaires. World Health Organization. Translations. Validation Studies. 


\section{RESUMO}

OBJETIVO: Testar a validade da versão brasileira do World Health Organization Quality of Life Instrument, abbreviated version (WHOQOL-BREF) em adultos com depressão maior, usando o modelo de Rasch.

MÉTODOS: Estudo utilizando dados secundários da amostra brasileira basal do “Longitudinal Investigation of Depression Outcomes”, constituída por 208 pacientes com depressão maior, recrutados em um serviço de atenção primária de Porto Alegre, RS, em 1999. Os instrumentos utilizados foram: a Center for Epidemiological Studies Depression Scale para avaliar a intensidade da depressão; a versão brasileira do WHOQOL-BREF, como medida de qualidade de vida genérica; e a Composite International Diagnostic Interview, version 2.1 para o diagnóstico de depressão.

RESULTADOS: Após usar a análise de Rasch, os quatro domínios do WHOQOL-BREF se mostraram adequados ao modelo de Rasch. Alguns itens necessitaram de ajustes: quatro itens foram recodificados (dor; finanças, serviços e transporte), 2 itens (trabalho e atividade) mostraram dependência de respostas, e 1 item foi retirado (sono), por apresentar sinal de multidimensionalidade.

CONCLUSÕES: A validação da versão brasileira do WHOQOL-BREF usando a análise de Rasch complementa os estudos prévios de validação, confirmando a importância deste instrumento como uma medida transcultural genérica de qualidade de vida.

DESCRITORES: Depressão. Qualidade de Vida. Questionários. Organização Mundial da Saúde. Tradução (Produto). Estudos de Validação.

\section{INTRODUCION}

The World Health Organization Quality of Life Instrument, abbreviated version (WHOQOL-BREF) is a generic quality of life (QoL) measure, which has been developed simultaneously in many cultures and languages by the World Health Organization. Although the WHOQOL-BREF has been developed using this methodology to ensure its cross-cultural validity, it was established in previous research using only Classical Test Theory (CTT). ${ }^{23}$ In consonance with international WHOQOL-BREF validation studies, the Brazilian Portuguese version was also validated using CTT., 10

Modern statistical analyses such as Rasch analysis has been pointed as a useful statistical method to yield measures that could be at the same time not influenced by sample nor by the scale.,20,24 Also this method may be a complementary tool for validation studies that used CTT. ${ }^{17,18}$ Based on the assumption of invariability posed by Rasch analysis, we can identify whether or not items that are part of a scale are affected by external factors such as presence of a depressive episode, age, gender and culture. Some authors have questioned the validity of QoL measure in depressed patients ${ }^{6}$ with the possibility of existing an overlap of depression and QoL constructs., ${ }^{4,11,12,15,16}$
Since major depression is an important public health problem in Brazil, where the estimates of point prevalence of this condition are between $3.5 \%$ to $9.7 \%$ and lifetime prevalence rate may be as high as $15 \%,{ }^{13}$ a valid QoL instrument is of great interest for Brazilian people. Regardless of the research context, any health policy or test of new treatment for these patients would benefit from information given by this measure that is not only focused on symptoms or functionality.

The objective of the present study was to assess the validity of the Brazilian version of WHOQOL-BREF in adults with major depression, using Rasch modeling

\section{METHODS}

Study using secondary data from the Longitudinal Investigation of Depression Outcomes (LIDO). The LIDO is a multicenter, cross-national observational study which followed patients with depressive disorders in primary care settings for 12 months in six countries. ${ }^{8}$ Patients attending a primary care service in the city of Porto Alegre, Southern Brazil, were screened for depression symptoms. Those meeting the inclusion criteria - new and/or untreated episode of depression 
and a score over 16 on the Center for Epidemiological Studies Depression Scale (CES-D) ${ }^{19}$ - were interviewed and assessed with a standardized diagnostic instrument for major depression, the Composite International Diagnostic Interview (CIDI). ${ }^{21}$

Continuous variables were age and years of education; and binary variables were gender, marital status, and self-report of health status.

The CES-D is a 20-item scale designed to measure symptoms of depression in community populations ${ }^{19}$ and was applied to measure the intensity of depression. The WHOQOL-BREF ${ }^{10,23}$ is a 26-item questionnaire distributed into four domains (physical, psychological, social relationships, and environment) and answers are scored using individualized five-point scales. Each subscale is scored positively. The CIDI, version 2.1, is a completely structured psychiatric diagnostic assessment developed for use in cross-national epidemiologic studies. Data from CIDI were used to assess diagnostic criteria for depression from the American Psychiatric Association (DSM-IV). ${ }^{1}$

A Rasch analysis was performed. The Rasch model is a one-dimensional model, first used in educational assessment, ${ }^{20}$ which asserts that the easier the item the more likely a person will give a correct response, and the more able the person, the more likely she/he will give a correct response on an item compared with a less able person. In the assessment of QoL, patients are presented with a range of items corresponding to differing facets of QoL. Thus, a person with higher QoL will have greater probability of answering positively (where positive reflects better QoL) than someone with lower QoL.

This model can be extended to analyze items with more than two categories, and this involves a "threshold" parameter, represented by the equal probability point between any two adjacent categories within an item. The model used in the present analysis is a further derivation, the Partial Credit Model. ${ }^{14}$

Three overall fit statistics are considered to determine the model fit. Two are item-person interaction statistics distributed as z-statistic with mean of zero and SD of 1 (indicating perfect fit to the model). The third one is an item-trait interaction statistic reported as $x^{2}$, reflecting the invariance across the trait (indicated by a no significant $x^{2}$ ). Besides, individual item-fit statistics are presented as residuals (acceptable within the range \pm 2.5 ) and as $x^{2}$ statistic (required also a non-significant $x^{2}$ ).

The boundaries between categories of responses are called "thresholds" and "disorder thresholds" may indicate that it will be necessary to collapse adjacent categories. Following this, data are fitted to the model to determine overall fit, and how well each item fits the model.

The Rasch model has some assumptions that need to be evaluated to ensure that an instrument has Rasch properties. The most commonly Rasch assumptions assessed are: a) unidimensionality; b) local independence; and c) invariability.

Unidimensionality is used to assess whether a single latent trait can explain all the data variance. The residuals are what remain when the "Rasch factor" has been removed from the data, and therefore, the first factor of the Principal Component Analysis (PCA) is the primary contributor to data variance, with the "Rasch factor" discounted. We take the items showing the highest positive correlation with the first component of PCA of the residuals, and the items with the highest negative loading items, and derive estimates for these two sets. These are compared to test if the assumption of unidimensionality holds by applying an independent t-test to each person pair of estimates. If less than $5 \%$ of the estimates are outside the range of \pm 1.96 , the scale is considered unidimensional.

Local independence means that when the ability influencing the performance is constant, responses to any pair of items are statistically independent. We check the residual correlation matrix to see if any values exceed +0.3 . This will indicate the presence of local dependency. If items are correlated in the residuals, we merge them into a "super" item through the subtest procedure, and see if improved fit is obtained. If so, it is a sign of local dependency and a violation of one of the Rasch assumptions.

Invariability implies that the parameters that characterize an item are not dependent on the distribution of persons' abilities and the parameters that characterize the persons are not dependent on the set of test items. To ensure the invariability of this measure, an analysis known as Differential Item Functioning (DIF) is performed. The statistical test used for detecting DIF is an analysis of variance (ANOVA) of the personitem deviation residuals with person factors (e.g., age, gender, country) and class intervals (e.g., group along the trait) as factors. All items were checked for DIF by gender, age and educational level as person factors. Items that do not yield the same item response function for two or more groups are violating the requirement for unidimensionality and invariability.

The internal consistency reliability of the scale was also determined based on the Person Separation Index (PSI), where the estimates on the logit scale for each person were used to calculate reliability.

Rasch analysis was undertaken using the Rasch Unidimensional Measurement Models (RUMM) 2020 package. $^{3}$

All patients agreeing to participate in the study signed a written consent including the objectives of the study. The local Research Ethics Committee approved the study. 


\section{RESULTS}

Table 1 summarizes the characteristics of the baseline sample. Our sample consisted predominantly of female, married, middle-aged, elementary school educated subjects with good health status and moderate levels of depression.

Of all domains of WHOQOL-BREF, only "physical” did not meet the requirements of the Rasch model, assessed by the summary of overall measures of fit statistics, where: total item $x^{2}$ was 86.9; chi-square p-value was 0.02; PSI is 0.79; P (independent t-test) ranged between 0.06 -and 0.12 .

Similarly, when analyzing individual item fit of all items, only the "sleep" item (residual=3.09; $x^{2}=23.66$; p-value $=0.0001$ ) did not fit the Rasch model. (Table 2)

Categories of responses were checked. Of the 26 items of BREF, “pain,” “finances,” “services,” and "transport” displayed disordered thresholds of response categories, and they required to be rescored to meet

Table 1. General characteristics of the baseline sample of depressed patients enrolled in the Longitudinal Investigation of Depression Outcomes Study. Porto Alegre, Southern Brazil, 1999.

\begin{tabular}{lc}
\hline Variable & $\begin{array}{c}\text { Depressed patients } \\
\mathrm{n}=208\end{array}$ \\
\hline Sex $(\%)$ & $52(25)$ \\
Male & $156(75)$ \\
Female & \\
Marital status (\%) & $106(51)$ \\
Married & $17(8.2)$ \\
Widowed & $22(10.6)$ \\
Separated & $12(5.8)$ \\
Divorced & $51(24.5)$ \\
Never Married & \\
Health status (\%) & $6(2.9)$ \\
Excellent & $34(16.3)$ \\
Very good & $132(63.5)$ \\
Good & $31(14.9)$ \\
Fair & $5(2.4)$ \\
Poor & \\
Years of education & $31.7 \pm 9.9$ \\
Mean \pm SD & $9.1 \pm 3.3$ \\
Mean \pm SD & \\
Mean \pm SD & $39.2 \pm 13.6$ \\
\hline
\end{tabular}

CES-D: Center for Epidemiological Studies Depression Scale
Rasch properties. By suppressing the middle response category in all these items their thresholds were ordered. Note that after rescoring these items, the response scale was shortened to $1-4$, while all remaining items maintained their original scoring 1-5.

All items were checked for DIF by age (younger than 45 years old vs. older than 45 years old), gender, and educational level (at least elementary education vs. elementary education and more). The items "positive feelings" and "support” displayed DIF for age and “energy” for gender. No item displayed DIF for educational level. No item has shown DIF for more than one factor. (Table 3)

As the physical domain items did not fit the Rasch model, all items were re-analyzed to conform to the Rasch model assumptions. In the analysis of the physical Domain, "activity" and "work" items showed correlations of 0.34 on person-item residual correlation matrix, indicating local dependency of responses (correlation $>0.3$ ). After the subtest analysis was performed, physical domain overall measures of fit improved, total item $x^{2}$ changed from 86.9 to 51.6; P from 0.02 to 0.57 ; PSI from 0.73 to 0.76 ; $\mathrm{P}$ (independent t-test) from $0.06-0.12$ to $-0.02-0.04$. Despite the improvement of all overall measures, the "sleep" item remained showing signals of misfit to the model (residual $=2.58 ; x^{2}=10.4 ; \mathrm{p}=0.32$ ). The deletion of the "sleep" item resulted in the best overall measures for the physical domain: total item $x^{2}$ changed from 51.6 to 38.9; P from 0.57 to 0.72 ; PSI remained 0.76 ; $\mathrm{P}$ (independent t-test) changed from $-0.02-0.04$ to 0.04-0.10. The "sleep" item misfit was due to multidimensionality.

The items of the psychological, environment, and social domains maintained their fit to the Rasch model, as illustrated in Table 4.

\section{DISCUSSION}

Our findings indicate the validity of WHOQOL-BREF as a measure of generic subjective QoL in depressed primary care patients in Brazil. Other studies that had similar purposes used CTT, small sample sizes (from 41 to 81 subjects) and patients from clinical settings. ${ }^{6,7,12,16}$

The analysis of all WHOQOL-BREF items in this Brazilian sample showed that only seven items (sleep, activity, work, pain, finances, services, and transport) did not meet Rasch requirements. Interestingly, four of them are items of the physical domain. This finding may be associated with the primary care setting, where patients were recruited in a visit with a general practitioner for physical complains which may or may not have been related to their depressive episode. ${ }^{5}$ An international study reported rates of depression with 
Table 2. Fit of WHOQOL-BREF items to the Rasch model of the baseline sample of depressed patients enrolled in the Longitudinal Investigation of Depression Outcomes Study. Porto Alegre, Southern Brazil, 1999.

\begin{tabular}{|c|c|c|c|c|c|c|}
\hline WHOQOL-BREF Item & Location & Residual & $X^{2}$ & $\mathrm{P}$ & \multicolumn{2}{|c|}{ Summary of overall fit statistics } \\
\hline Overall QoL & -0.68 & 1.09 & 4.83 & 0.44 & & \\
\hline General health & 0.68 & -0.94 & 6.28 & 0.28 & & \\
\hline \multicolumn{7}{|l|}{ Physical } \\
\hline Pain* & -0.48 & 1.23 & 6.22 & 0.72 & Total Item $x^{2}$ & 86.9 \\
\hline Medication & -0.33 & 0.94 & 7.64 & 0.57 & Chi-square $\mathrm{P}$ & 0.02 \\
\hline Energy & 0.32 & 0.16 & 12.73 & 0.18 & PSI & 0.79 \\
\hline Mobility & -0.67 & 0.01 & 13.70 & 0.13 & t-test P** & $0.06 ; 0.12$ \\
\hline Sleep & 0.41 & 3.09 & 23.66 & 0.0001 & & \\
\hline Activities & 0.56 & -1.28 & 12.33 & 0.20 & & \\
\hline Work capacity & -0.48 & -1.51 & 10.61 & 0.30 & & \\
\hline \multicolumn{7}{|l|}{ Psychological } \\
\hline Positive feelings & 0.57 & 0.35 & 5.40 & 0.80 & Total Item $x^{2}$ & 47.35 \\
\hline Spirituality & -0.40 & -0.94 & 6.63 & 0.68 & Chi-square $p$ & 0.72 \\
\hline Thinking & -0.11 & 1.33 & 9.32 & 0.41 & PSI & 0.73 \\
\hline Bodily image & -0.45 & 0.71 & 6.99 & 0.64 & t-test P** & $0.01 ; 0.07$ \\
\hline Self-esteem & 0.10 & -0.13 & 6.48 & 0.69 & & \\
\hline Negative feelings & 0.29 & 0.69 & 12.53 & 0.19 & & \\
\hline \multicolumn{7}{|l|}{ Environment } \\
\hline Safety & 0.36 & 0.46 & 1.80 & 0.99 & Total Item $x^{2}$ & 49.3 \\
\hline Environment & 0.17 & 1.46 & 5.29 & 0.81 & Chi-square $\mathrm{P}$ & 0.98 \\
\hline Finances* & 0.81 & 0.42 & 7.75 & 0.56 & PSI & 0.63 \\
\hline Information & -0.67 & 0.59 & 6.43 & 0.70 & t-test P** & $0.05 ; 0.11$ \\
\hline Leisure & 0.50 & 0.02 & 7.34 & 0.60 & & \\
\hline Home & -0.41 & -0.99 & 6.33 & 0.71 & & \\
\hline Services* & -0.51 & -0.16 & 9.34 & 0.41 & & \\
\hline Transport* & -0.24 & 1.74 & 5.02 & 0.83 & & \\
\hline \multicolumn{7}{|l|}{ Social } \\
\hline Relationships & -0.14 & -0.58 & 7.83 & 0.45 & Total Item $x^{2}$ & 24.9 \\
\hline Sexual activity & 0.30 & 2.03 & 9.50 & 0.30 & Chi-square $\mathrm{P}$ & 0.35 \\
\hline \multirow[t]{2}{*}{ Support } & -0.16 & 0.05 & 7.60 & 0.37 & PSI & 0.58 \\
\hline & & & & & t-test $\mathrm{P} * *$ & $0.01 ; 0.07$ \\
\hline
\end{tabular}

* Items that needed to be rescored due to disordered thresholds of response categories

** $\mathrm{P}$ of test for unidimensionality, shown as $95 \% \mathrm{Cl}$, probability of 0.05 must be included in the interval Bold: items that did not fit the model PSI: Person Separation Index

somatic manifestations from $45 \%$ to $95 \%$ in the countries studied. ${ }^{22}$ The deletion of the "sleep" item and its inclusion as a separate item may be justifiable by its multidimensionality since "sleep" may be a content from physical or/and psychological domains.

The conciliation of conceptual model and empiric evidence is a challenge to researchers. Although the inclusion of these excluded items had a conceptual reason.
Table 3. Adjusted WHOQOL-BREF response categories after the Rasch analysis. Porto Alegre, Southern Brazil, 1999.

\begin{tabular}{lccccc}
\hline WHOQOL-BREF Item & \multicolumn{5}{c}{ Response Scale } \\
\hline Pain & 1 & 2 & 3 & 3 & 4 \\
Finances & 1 & 2 & 3 & 3 & 4 \\
Services & 1 & 2 & 2 & 3 & 4 \\
Transport & 1 & 2 & 2 & 3 & 4 \\
All remaining items & 1 & 2 & 3 & 4 & 5 \\
\hline
\end{tabular}


Table 4. Fit of WHOQOL items adjusted by the Rasch model of the baseline sample of depressed patients enrolled in the Longitudinal Investigation of Depression Outcomes Study. Porto Alegre, Southern Brazil, 1999.

\begin{tabular}{|c|c|c|c|c|c|c|}
\hline WHOQOL-BREF adjusted Item & Location & Residual & $X^{2}$ & $\mathrm{P}$ & \multicolumn{2}{|c|}{ Summary of overall fit statistics for domains } \\
\hline \multicolumn{7}{|l|}{ Overall } \\
\hline Overall QoL & -0.68 & 1.09 & 4.83 & 0.44 & & \\
\hline General health & 0.68 & -0.94 & 6.28 & 0.28 & & \\
\hline \multicolumn{7}{|l|}{ Physical } \\
\hline Activities + work capacity* & 0.63 & -0.82 & 3.65 & 0.93 & Total Item $x^{2}$ & 38.9 \\
\hline Pain & -0.56 & 0.92 & 9.43 & 0.40 & Chi-square $\mathrm{P}$ & 0.72 \\
\hline Medication & -0.13 & 0.71 & 11.65 & 0.23 & PSI & 0.76 \\
\hline Energy & 0.52 & 0.44 & 8.05 & 0.53 & t-test $\mathrm{P} * *$ & $0.04-0.10$ \\
\hline Mobility & -0.47 & 0.31 & 6.19 & 0.72 & & \\
\hline \multicolumn{7}{|l|}{ Psychological } \\
\hline Positive feelings & 0.57 & 0.35 & 5.40 & 0.80 & Total Item $x^{2}$ & 47.35 \\
\hline Spirituality & -0.40 & -0.94 & 6.63 & 0.68 & Chi-square $\mathrm{P}$ & 0.72 \\
\hline Thinking & -0.11 & 1.33 & 9.32 & 0.41 & PSI & 0.73 \\
\hline Bodily image & -0.45 & 0.71 & 6.99 & 0.64 & t-test $\mathrm{P} * *$ & $0.01-0.07$ \\
\hline Self-esteem & 0.10 & -0.13 & 6.48 & 0.69 & & \\
\hline Negative feelings & 0.29 & 0.69 & 12.53 & 0.19 & & \\
\hline \multicolumn{7}{|l|}{ Environment } \\
\hline Safety & 0.38 & 0.27 & 1.55 & 1.00 & Total Item $\mathrm{x}^{2}$ & 43.1 \\
\hline Environment & 0.16 & 1.26 & 7.36 & 0.60 & Chi-square $\mathrm{P}$ & 0.99 \\
\hline Finances & 0.83 & 0.52 & 10.84 & 0.29 & PSI & 0.63 \\
\hline Information & -0.67 & 0.35 & 4.47 & 0.88 & t-test $\mathrm{P} * *$ & $0.05-0.11$ \\
\hline Leisure & 0.51 & 0.02 & 5.94 & 0.75 & & \\
\hline Home & -0.43 & -1.09 & 4.78 & 0.85 & & \\
\hline Services & -0.56 & -0.09 & 3.77 & 0.93 & & \\
\hline Transport & -0.22 & 1.11 & 4.44 & 0.88 & & \\
\hline \multicolumn{7}{|l|}{ Social } \\
\hline Relationships & -0.14 & -0.58 & 7.83 & 0.45 & Total Item $x^{2}$ & 24.9 \\
\hline Sexual activity & 0.30 & 2.03 & 9.50 & 0.30 & Chi-square P & 0.35 \\
\hline \multirow[t]{2}{*}{ Support } & -0.16 & 0.05 & 7.60 & 0.37 & PSI & 0.58 \\
\hline & & & & & t-test P** & $0.01-0.07$ \\
\hline
\end{tabular}

PSI: Person Seperation Index

* Subtest analysis

** $\mathrm{P}$ of test for unidimensionality, shown as $95 \% \mathrm{Cl}$, probability of 0.05 must be included

The exclusion and inclusion of items clearly reduce the comparability of measures between different populations, thus leading researchers to make concessions, depending on research purpose.

The present study did not re-test the original four-domain structure of WHOQOL-BREF, which can be a limitation, despite the fact that there is not a literature consensus on the most suitable method to evaluate instrument dimensionality. ${ }^{9}$ Hence, we opted to maintain the 4-domain structure because, besides being the most conservative approach, it is the most studied one. ${ }^{25}$

In conclusion, the validation of the WHOQOL-BREF Brazilian version using Rasch analysis complements previous validation studies, evidencing the robustness of this instrument as a generic cross-cultural QoL measure. 


\section{REFERENCES}

1. American Psychiatric Association. Diagnostic and statistical manual of mental disorders. Washington, DC; 1994.

2. Andrich D. A rating formulation for ordered response categories. Psichometrika. 1978;43(4):561-73. DOI: 10.1007/BF02293814

3. Andrich D, Sheridan B, Luo G. RUMM 2020: a Windows program for analysing item response data according to Rasch Unidimensional Measurement Models. Perth, Western Australia: RUMM Laboratory; 2004.

4. Angermeyer MC, Holzinger A, Matschinger $\mathrm{H}$, StenglerWenzke K. Depression and quality of life: results of a follow-up study. Int / Soc Psychiatry. 2002;48(3):18999. DOI: $10.1177 / 002076402128783235$

5. Aragones E, Labad A, Piñol JL, Lucena C, Alonso Y. Somatized depression in primary care attenders. J Psychosom Res. 2005;58(2):145-51. DOI: 10.1016/ j.jpsychores.2004.07.010

6. Atkinson $\mathrm{M}$, Zibin $\mathrm{S}$, Chuang $\mathrm{H}$. Characterizing quality of life among patients with chronic mental illness: a critical examination of the self-report methodology. Am J Psychiatry. 1997;154(1):99-105.

7. Berlim MT, Pavanello DP, Caldieraro MA, Fleck MP. Reliability and validity of the WHOQOL BREF in a sample of Brazilian outpatients with major depression. Qual Life Res. 2005;14(2):561-4. DOI: 10.1007/ s11136-004-4694-y

8. Chisholm D, Amir M, Fleck M, Herrman H, Lomachenkov A, Lucas R, et al. Longitudinal investigation of depression outcomes (The LIDO Study) in primary care in six countries: comparative assessment of local health systems and resource utilization. Int J Methods Psychiatr Res. 2001;10(2):5971. DOI: 10.1002/mpr.101

9. Coste J, Bouée S, Ecosse E, Leplège A, Pouchot J. Methodological issues in determining the dimensionality of composite health measures using principal component analysis: case illustration and suggestions for practice. Qual Life Res. 2005;14(3):641-54. DOI: 10.1007/s11136-004-1260-6

10. Fleck MP, Louzada S, Xavier M, Chachamovich E, Vieira G, Santos L, et al. Aplicação da versão em português do instrumento abreviado de avaliação da qualidade de vida "WHOQOL-bref". Rev Saude Publica. 2000;34(2):178-83. DOI: 10.1590/S003489102000000200012

11. Heinonen $\mathrm{H}$, Aro AR, Aalto AM, Uutela A. Is the evaluation of the global quality of life determined by emotional status? Qual Life Res. 2004;13(8):1347-56. DOI: 10.1023/B:QURE.0000040788.12947.b9

12. Kuehner C. Subjective quality of life: validity issues with depressed patients. Acta Psychiatr Scand. 2002;106(1):62-70. DOI: 10.1034/j.16000447.2002.02204.x
13. Mari J, Jorge MR, Kohn R. Epidemiologia dos transtornos psiquiátricos em adultos. In: Mello MFM, Mello AAF, Kohn R, eds. Epidemiologia da saúde mental no Brasil. Porto Alegre: Artmed; 2007.

14. Masters GN. Rasch model for partial credit scoring. Psychometrika. 1982;47(2):149-74. DOI: 10.1007/ BF02296272

15. Masthoff ED, Trompenaars FJ, Van Heck GL, Hodiamont PP, De Vries J. Quality of life and psychopathology: investigations into their relationship. Aust N Z J Psychiatry. 2006;40(4):333-40. DOI: 10.1111/j.1440-1614.2006.01799.x

16. Naumann VJ, Byrne GJ. WHOQOL-BREF as a measure of quality of life in older patients with depression. Int Psychogeriatr. 2004;16(2):159-73. DOI: 10.1017/ S1041610204000109

17. Norquist JM, Fitzpatrick R, Dawson J, Jenkinson C. Comparing alternative Rasch-based methods vs raw scores in measuring change in health. Med Care. 2004;42(1 Supp):I25-36.

18. Prieto L, Alonso J, Lamarca R. Classical test theory versus Rasch analysis for quality of life questionnaire reduction. Health Qual Life Outcomes. 2003;1:27. DOI: 10.1186/1477-7525-1-27

19. Radloff LS. The CES-D scale: a self report depression scale for research in the general population. Appl Psych Meas. 1977;1(3):385-401. DOI: 10.1177/01466 2167700100306

20. Rasch G. Probabilistic models for some intelligence and attainment tests. Copenhagen: Danish Institute for Educational Research; 1960.

21. Robins LN, Wing J, Wittchen HU, Helzer JE, Babor TF, Burke J, et al. The Composite International Diagnostic Interview. An epidemiologic Instrument suitable for use in conjunction with different diagnostic systems and in different cultures. Arch Gen Psychiatry. 1988;45(12):1069-77.

22. Simon GE, VonKorff M, Piccinelli M, Fullerton C, Ormel J. An international study of the relation between somatic symptoms and depression. $N$ Eng/ / Med. 1999;341(18):1329-35. DOI: 10.1056/ NEJM199910283411801

23. Skevington SM, Lotfy M, O'Connell KA. The World Health Organization's WHOQOL-BREF quality of life assessment: psychometric properties and results of the international field trial. A report from the WHOQOL group. Qual Life Res. 2004;13(2):299-310. DOI: 10.1023/B:QURE.0000018486.91360.00

24. Smith JE. Metric development and score reporting in Rasch measurement. J of App Measur. 2000;1(3):303-26.

25. Yao G, Wu CH. Factorial invariance of the WHOQOLBREF among disease groups. Qual Life Res. 2005;14(8):1881-8. DOI: 10.1007/s11136-005-3867-7

Rocha NS was supported by Coordenação de Aperfeiçoamento de Pessoal de Nível Superior (CAPES - Process 0677/04-3; doctarate scholarship), Fundo de Incentivo à Pesquisa - Hospital de Clínicas de Porto Alegre, and the University of Edinburgh. 